\title{
Remote estimation of carbon dioxide uptake of terrestrial ecosystems
}

Martín F. Garbulsky ${ }^{1,2,4}$, Josep Peñuelas ${ }^{1}$, Dario Papale ${ }^{3}$, Iolanda Filella ${ }^{1}$

${ }^{1}$ Unitat d'Ecofisiologia CSIC-CEAB-CREAF, CREAF (Centre de Recerca Ecològica i Aplicacions Forestals), Universitat Autònoma de Barcelona, 08193 Bellaterra, Spain

${ }^{2}$ Faculty of Agronomy, University of Buenos Aires, Argentina

${ }^{3}$ Department of Forest Science and Environment, University of Tuscia, 01100 Viterbo, Italy

${ }^{4}$ Corresponding author: CREAF, Edifici C -Universitat Autònoma de Barcelona, 08193 Bellaterra, Spain

Email:martin@creaf.uab.cat

Tel: 0034935813420

Fax: 0034935814151

Keywords: $\mathrm{CO}_{2}$ uptake, eddy covariance, carbon cycle, remote sensing, vegetation, primary productivity, radiation use efficiency, MODIS, Mediterranean forests.

Running title: Estimation of $\mathrm{CO}_{2}$ uptake of ecosystems

Submitted for publication to Global Change Biology (21st May, 2007) 


\section{Abstract}

2 The estimation of the carbon balance in ecosystems, regions, and the biosphere is currently

3 one of the main concerns in the study of the ecology of global change. Current remote

4 sensing methodologies for estimating gross primary productivity are not satisfactory

5 because they rely too heavily on (i) the availability of climatic data, (ii) the definition of

6 land-use cover, and (iii) the assumptions of the effects of these two factors on the radiation-

7 use efficiency of vegetation (RUE). A new methodology is urgently needed that will

8 actually assess RUE and overcome the problems associated with the capture of fluctuations

9 in carbon absorption in space and over time. Remote sensing techniques such as the widely

10 used reflectance vegetation indices (e.g., NDVI, EVI) allow green plant biomass and

11 therefore plant photosynthetic capacity to be assessed. Nevertheless, detecting how much of

12 this capacity is actually realized is a much more challenging goal. The Photochemical

13 Reflectance Index (PRI) derived from freely available satellite information (MODIS

14 sensor) presented an exponential relationship with the RUE. Thus, we show that it is

15 possible to estimate RUE in real time and therefore actual carbon uptake at ecosystem,

16 regional, and biosphere levels using the PRI. This conceptual and technological

17 advancement avoids the need to rely on either the sometimes unreliable maximum RUE for

18 each ecosystem, hard-to-obtain climate data, or on imprecise land-use/land-cover data. 
Introduction

2 The scientific community is devoting huge amounts of time and resources to assessing the

3 global carbon budget in a context of climate change (Boisvenue and Running, 2006, Ciais

4 et al., 2005, Schulze, 2006). Current remote sensing methodologies for estimating gross

5 primary productivity mostly depend on absorbed radiation and the efficiency of conversion

6 into carbon-based compounds as proposed in Monteith's model (Monteith, 1977). Most

7 methodologies rely heavily on (i) the availability of climatic data, (ii) the definition of land-

8 use cover to estimate the radiation-use efficiency of the vegetation (RUE), and/or (iii)

9 assumptions of the effects of both these previous factors on the RUE. These methodologies

10 are thus over-dependent on the availability of climatic data, the quality of land-cover data,

11 and assumptions regarding RUE (Heinsch et al., 2006).

13 Recent scientific work at leaf and plant scales reveals that it is possible to estimate

14 radiation-use efficiency remotely by using a photochemical reflectance index (PRI)

15 (Gamon et al., 1992, Peñuelas et al., 1995, Peñuelas et al., 1997). The PRI derived from

16 new breed narrow-band spectroradiometers are increasingly being used as photosynthetic

17 performance indicators at ecosystem level (Asner et al., 2004). By complementing the

18 NDVI estimation of green biomass -and therefore of potential productivity (Gamon et al.,

19 1995)- with PRI it is now possible to improve assessments from airborne sensors of the

20 carbon uptake in many of the world's ecosystems (Nichol et al., 2002, Nichol et al., 2006,

21 Rahman et al., 2001). The global coverage of satellites has dramatically improved our

22 capacity to extend PRI-based estimations of vegetation radiation-use efficiency and carbon

23 fluxes to all areas of the globe. However, the highly interesting possibilities offered by 
1 satellite images are still little used and under evaluation (Drolet et al., 2005, Rahman et al.,

2 2004). Net Primary Productivity estimations for ecosystems with low seasonality in their

3 radiation interception (e.g., evergreen forests) but high seasonality in their carbon

4 absorption could especially benefit from this approach. In other ecosystems, where high

5 seasonality in the leaf-area index is the main driver of carbon absorption, the traditional

6 NDVI (Tucker et al., 1985)or EVI (Sims et al., 2006b) approach seems robust enough for

7 arriving at a good estimation of the GPP (Sims et al., 2006a).

9 We evaluated the worth of the PRI derived from satellite MODIS sensors as an estimator of

10 the radiation-use efficiency in a Mediterranean forest in which (a) seasonal variation in

11 radiation interception is very low and (b) carbon absorption has important seasonal

12 fluctuations that are mainly determined by water deficits during summer (Rambal et al.,

13 2003) and very short periods of low temperatures in winter (Ogaya and Peñuelas, 2003),

14 which provoke significant periods of very low photosynthesis. Because of the negligible

15 changes in structure and leaf area index and thus in radiation interception, it is of great

16 importance in this forest to have accurate measurements of radiation-use efficiency. This is

17 a paradigmatic case in which to look for an alternative to the use of intercepted radiation as

18 the only remote sensing input driving global models estimating carbon fluxes, and

19 therefore, a leading case in which to produce a real time estimation of carbon absorption by

20 vegetation. 


\section{$1 \quad$ Materials and Methods}

2 We analyzed eddy covariance data of carbon fluxes and MODIS (Moderate Resolution

3 Imaging Spectroradiometer) remote sensing data in the Mediterranean forest of

4 Castelporziano in central Italy $\left(41^{\circ} 42^{\prime}\right.$ lat; $12^{\circ} 22^{\prime}$ long; mean annual temperature $15.6^{\circ} \mathrm{C}$;

5 mean annual precipitation $767 \mathrm{~mm}$ ) for the period January 2001- December 2002. The

6 vegetation is a 10-meter-tall broadleaf evergreen forest mainly dominated by holm oak

7 (Quercus ilex (Tirone et al., 2003)).

9 We used the PRI as a remotely sensed estimator of the RUE in the model proposed by

10 Monteith (Monteith, 1977).

$$
\mathrm{RUE}=\mathrm{GPP} / \mathrm{APAR}
$$

12 where RUE is the radiation-use efficiency, GPP is the gross primary productivity, and

13 APAR is the photosynthetic active radiation absorbed by the vegetation, as calculated by

14 the product of PPAR (the fraction of the PAR absorbed by the canopy, estimated from the

15 NDVI (Myneni et al., 2002)) and the PAR derived from the eddy covariance tower data.

16 We used the spectral index EVI as an alternative linear estimator of the PPAR (Xiao et al.,

17 2005). The GPP was estimated from the total $\mathrm{CO}_{2}$ fluxes from the eddy covariance tower

18 (Valentini et al., 2007) and ecosystem respiration and storage estimated (Papale et al., 2006,

19 Reichstein et al., 2005) and climate data at 30 minutes resolution.

21 An average of the GPP and PAR half-hour values was calculated for days having MODIS

22 surface reflectance data (MODO9A1 band $1(620-670 \mathrm{~nm})$, band $2(841-876 \mathrm{~nm})$, band 3

$23(459-479 \mathrm{~nm}))$. These images consist of 8-day composites constructed from the daily 
1 surface reflectance for specific dates. The Normalized Difference Vegetation Index (NDVI

$2=($ band $2-$ band 1$) /($ band $2+$ band 1$)$ and the Enhanced Vegetation Index $(E V I=2.5 *($ band

32 - band 1$) /\left(\right.$ band $2+6 *$ band $1-7.5^{*}$ band 3 ) were calculated from those images and

4 assigned to those dates. The temporal resolution of the analysis is 8 days, which

5 corresponds to that of the MODO9A1 images. Theoretically, this represents 46 days per

6 year; however, we only obtained data for 33 days in 2001 and 17 in 2002 due to a lack of

7 data for one or other of the sources. For all the MODIS data, quality flags were checked to

8 discard low quality images.

9

10 To calculate the Photochemical Reflectance Index (PRI = (band 11- band 12)/ (band $11+$

11 band 12)), we extracted the MODIS daily calibrated radiance (MODIS Terra L1b -

12 MODO21 km V005) for bands $11(526-536 \mathrm{~nm})$ and $12(546-556 \mathrm{~nm})$ for the pixel $(1 \mathrm{x} 1$

$13 \mathrm{~km}$ ) that included the tower. We used for the calculation the same specific dates as for the

14 NDVI and EVI calculations. The atmospheric effects on bands 11 and 12 were similar

15 because they are positioned closely together in the spectrum. Moreover, atmospheric

16 transmissivity in this part of the spectrum is very high and stable and thus its atmospheric

17 correction would have very little effect (Vermote et al., 2002). On comparing the surface

18 reflectance (MODO9A1) and the calibrated radiance (MODO21KM) for the years 2001-

192004 for band $4(545-565 \mathrm{~nm})$, evidence emerged that a linear adjustment between them

20 exists $\left(\mathrm{r}^{2}=0.76, \mathrm{n}=68, \mathrm{p}<0.0000001\right)$. Thus, we considered that the calibrated radiance at

21 these bands could be used without atmospheric correction in the calculation of a normalized

22 spectral index such as the PRI. 
1 We evaluated the PRI as an estimator of the RUE (eq. [1]) and then parametrized the

2 relationship by means of a subset of the data and a linear regression analysis for 2002 . We

3 applied the parametrized model to the rest of the data as per the model proposed by

4 Monteith and compared it with the estimations regularly made by the MODIS team

5 (Heinsch et al., 2003) (MODIS17A2, version 4.8). We compared the final GPP product for

6 both methodologies, however we cannot rule out differences in both estimations due to the

7 use of different PAR data and different fPAR estimations. Fair correlations were found

8 between incident radiations measured by the towers and those derived from the global

9 climate model (GEOS-4) included in the MODIS GPP product (Heinsch et al., 2006). 


\section{$1 \quad$ Results and Discussion}

2 GPP ranged from 1.5 to $8 \mathrm{~g} \mathrm{C} \mathrm{m}^{-2} \mathrm{~d}^{-1}$ (Fig. 1a), with minimum values occurring mainly in

3 winter and local minimum in summer. Radiation absorption, as estimated from NDVI and

4 EVI, were very stable throughout the year (Fig. 1b). The GPP/APAR ratio ranged between

$5 \quad 0.3$ and $1.7 \mathrm{~g} \mathrm{C} \mathrm{MJ}^{-1}$, with minimum values in summer and maximum values in winter or

6 spring (Fig. 1c). The seasonality of the PRI was similar to that of the GPP/APAR ratio

7 throughout the study period. The PRI was a good reflection of seasonal changes in the

8 timing and magnitude of GPP/APAR (Fig. 1c). The seasonal coefficients of variation

9 (standard deviation/mean) were only 3\% for NDVI and $12 \%$ for EVI, but reached $66 \%$ for

10 PRI and $46 \%$ for GPP/APAR.

12 The PRI was a good exponential estimator of the GPP/PAR ratio (Fig. 2c). The NDVI was

13 not correlated and the EVI was slightly negatively correlated to the GPP/PAR, although the

14 latter accounted for much less variance than the PRI (Fig. 2). Positive exponential

15 regressions between the GPP/PAR and the PRI were found also for each year in question.

16 In order to reduce uncertainties associated with seasonal changes in incident radiation or

17 the view zenith angle, we also tested the ability of the PRI product to estimate the

18 GPP/PAR ratio for the summer months only (i.e. PAR $>7 \mathrm{MJ} \mathrm{m}^{-2}$ day $^{-1}$ ). In a positive

19 exponential regression, PRI still explained $45 \%$ of the variance of GPP/PAR $(n=32, p<$

$\left.200.0001, \operatorname{RMSE}=0.1 \mathrm{~g} \mathrm{C} \mathrm{MJ}^{-1}\right)$. PRI was also a good estimator of RUE (GPP/APAR)

$21(\mathrm{n}=23 ; \mathrm{r} 2=0.58, \mathrm{~F}=29.09, \mathrm{p}<0.0001)$ for 2001 in an evergreen needleleaf forest (Loobos,

22 Netherlands, Pinus sylvestris stand) where we also test the ability of the PRI to estimate

23 GPP/APAR following the same procedure described for Castelporziano holm oak forest. 
2 The use of an exponential estimation of the RUE by means of the PRI for 2002 (RUE [g C

$\left.\left.3 \mathrm{MJ}^{-1}\right]=0.62 \mathrm{e}^{21.25 \times \text { PRI }} \mathrm{n}=20 ; \mathrm{r}^{2}=067 ; \mathrm{p}<0.0001\right)$ together with PAR and NDVI strongly

4 improved the MODIS NASA GPP estimate for 2001 (Fig. 3). The use of PRI significantly

5 reduced the error in the estimate of the daily GPP measured in the flux tower when

6 compared to the MODIS NASA GPP product (MODIS17) based on the fPAR product and

7 the RUE estimate based on the maximum ecosystem RUE, the VPD, and the minimum

8 temperature.

10 The up-scaling of the previous work at leaf and plant level (Gamon et al., 1995, Peñuelas et 11 al., 1995, Peñuelas et al., 1997) to the 1 x $1 \mathrm{~km}$ pixel level was successful, despite a number 12 of a priori expected problems. Unlike vegetation indexes, which are mainly related to the 13 red-edge reflectance of the vegetation, the PRI has a very low signal. Nevertheless, despite 14 this low signal and the coarse resolution of MODIS images, the PRI produced a very 15 accurate signal of a leaf-level process, related to the dissipation of radiation excess by 16 plants and consequent xanthophyll pigment epoxidation. It is also likely that PRI scales

17 with seasonal pigment changes (e.g. carotenoids/chlorophyll a ratio) and other related

18 photosynthetic processes with stronger signal (Filella et al., 2004, Sims and Gamon, 2002).

19 A second possible problem relates to the temporal matching between data from the carbon

20 flux and the satellite spectral data. The MODIS Terra platform passes over in the morning

21 and thus may not capture the full day gas exchange performance. Furthermore, in spite of

22 the high availability of remote sensing data provided by different satellites, there are still a

23 number of problems regarding the use of this data, above all associated with computational 
1 difficulties when performing atmospheric corrections. Corrected reflectances from MODIS

2 are available only for seven of its 36 bands, and the corrected data for constructing narrow-

3 band spectral indexes such as the PRI are not available yet. Our data suggests that this

4 problem can be overcome by working with spectral bands closely located in the green

5 portion of the electromagnetic spectrum, such as those used in the PRI calculation, in order

6 to make correction unnecessary. Therefore, this fact makes the data and the calculations

7 available for everybody by accessing to MODIS data webpage. Previous work (Drolet et

8 al., 2005) also provides evidence that atmospheric correction for close wavelengths is not

9 necessary. A fourth issue is the consistent relationship between ground and satellite data

10 that was found despite the fact that soil and plant respiration may produce a significant

11 scatter in the relationship between PRI and carbon uptake. This is due to the fact that, while

12 PRI tracks gross photosynthesis (i.e., direct carbon uptake not including respiratory loss),

13 conventional flux sampling methods provide the net $\mathrm{CO}_{2}$ flux (i.e., combined

14 photosynthetic carbon gain and respiratory loss) from the sampling area and ecosystem

15 respiration is estimated from environmental variables (temperature and water availability)

16 and extrapolation of night-time values of ecosystem respiration into the daytime

17 (Reichstein et al., 2005). Finally, there are also the confounding physical effects of canopy

18 structure, leaf movement, sun angle, and soil background that may also significantly

19 influence the PRI signal (Gamon et al., 1992). Areas with low vegetation cover would

20 present problems when using this methodology (Filella et al., 2004, Sims et al., 2006a). An

21 examination of a range of ecosystems reveals that the utility of the PRI will vary with the

22 ecosystem in question due to contrasting environmental constraints, evolutionary strategies,

23 and light-use efficiencies. A comprehension of ecophysiological principles will be needed 
1 to fully reveal these patterns and it is likely that new remote-sensing approaches

2 incorporating PRI will contribute to this understanding.

4 In this study we provide evidence that a real time estimation of carbon uptake can be

5 carried out at ecosystem, regional, and global levels on the basis of freely available remote

6 sensing data that complements traditional well-established vegetation indices such as the

7 NDVI with the PRI. Our results may thus be of great importance and have multiple

8 applications such as the estimation of the productivity $\left(\mathrm{CO}_{2}\right.$ fixation) of any region or the

9 detection of the effects of climatic change on vegetation that may occur before leaf-area

10 reduction. But these results provide not only a significant technological improvement; they

11 also provide an important conceptual advance since they show that optical signals

12 incorporate information on vegetation physiological performance (photosynthetic rates

13 linked to changes in pigment ratios) at an ecosystem scale. Our results warrant thus a

14 generalized study of PRI performance in multiple ecosystems and conditions in order to

15 confirm the high expectations raised by the results we present here.

16

17 Acknowledgments: M.F.G. is supported by the Programme Alßan, the European Union

18 Programme of High Level Scholarships for Latin America (E05D053374AR) and by the

19 University of Buenos Aires. This work was funded under grants from the European Union,

20 the Catalan Government, the BBVA Foundation and the Spanish Ministry of Education and

\section{Science.}




\section{References}

2 Asner, G. P., Nepstad, D., Cardinot, G. \& Ray, D. (2004) Drought stress and carbon uptake in an Amazon forest measured with spaceborne imaging spectroscopy. Proceedings of the National Academy of Sciences of the United States of America, 101, 60396044.

Boisvenue, C. \& Running, S. W. (2006) Impacts of climate change on natural forest productivity - evidence since the middle of the $20^{\text {th }}$ century. Global Change Biology, 12, 862.

Ciais, P., Reichstein, M., Viovy, N., Granier, A., Ogee, J., Allard, V., Aubinet, M., Buchmann, N., Bernhofer, C., Carrara, A., Chevallier, F., De Noblet, N., Friend, A. D., Friedlingstein, P., Grunwald, T., Heinesch, B., Keronen, P., Knohl, A., Krinner, G., Loustau, D., Manca, G., Matteucci, G., Miglietta, F., Ourcival, J. M., Papale, D., Pilegaard, K., Rambal, S., Seufert, G., Soussana, J. F., Sanz, M. J., Schulze, E. D., Vesala, T. \& Valentini, R. (2005) Europe-wide reduction in primary productivity caused by the heat and drought in 2003. Nature, 437, 529-533.

Drolet, G. G., Huemmrich, K. F., Hall, F. G., Middleton, E. M., Black, T. A., Barr, A. G. \& Margolis, H. A. (2005) A MODIS-derived photochemical reflectance index to detect inter-annual variations in the photosynthetic light-use efficiency of a boreal deciduous forest. Remote Sensing of Environment, 98, 212-224.

Filella, I., Peñuelas J., Llorens L. \& Estiarte M. (2004) Reflectance assessment of seasonal and annual changes in biomass and $\mathrm{CO}_{2}$ uptake of a Mediterranean shrubland submitted to experimental warming and drought. Remote Sensing of Environment, 90, 308-318. 
1 Gamon, J. A., Field, C. B., Goulden, M., Griffin, K., Hartley, A., Joel, G., Peñuelas, J. \&

2 Valentini, R. (1995) Relationships between NDVI, canopy structure, and

3 photosynthetic activity in three Californian vegetation types. Ecological

$4 \quad$ Applications, 5, 28-41.

5 Gamon, J. A., Peñuelas, J. \& Field, C. B. (1992) A narrow-waveband spectral index that

6 tracks diurnal changes in photosynthetic efficiency. Remote Sensing of

$7 \quad$ Environment, 41, 35-44.

8 Heinsch, F. A., M. Zhao, S. W. Running, J. S. Kimball, R. R. Nemani, K. J. Davis, P. V.

9 Bolstad, B. D. Cook, A. R. Desai, D. M. Ricciuto, B. E. Law, W. C. Oechel, H. J.

10 Kwon, H. Luo, S. C. Wofsy, A. L. Dunn, J. W. Munger, D. D. Baldocchi, L. Xu, D.

11 Y. Hollinger, A. D. Richardson, P. C. Stoy, M. B. S. Siqueira, R. K. Monson, S. P.

12 Burns \& Flanagan, L. B. (2006) Evaluation of remote sensing based terrestrial

13 productivity from MODIS using regional tower eddy flux network observations.

14 IEEE Transactions on Geoscience and Remote Sensing, 44, 1908-1925

15 Heinsch, F. A., Reeves, M., Votava, P., Kang, S., Milesi, C., Zhao, M., Glassy, J., Jolly, W.

16 M., Loehman, R., Bowker, C. F., Kimball, J. S., Nemani, R. R. \& Running, S. W.

17 (2003) User's Guide GPP and NPP (MOD17A2/A3) Products NASA MODIS Land

18 Algorithm. Missoula, MT, University of Montana.

19 Monteith, J. L. (1977) Climate and the efficiency of crop production in Britain. Philosophical Transactions of the Royal Society B: Biological Sciences, 281, 277-

22 Myneni, R. B., Hoffman, S., Knyazikhin, Y., Privette, J. L., Glassy, J., Tian, Y., Wang, Y., 23 Song, X., Zhang, Y. \& Smith, G. R. (2002) Global products of vegetation leaf area 
and fraction absorbed PAR from year one of MODIS data. Remote Sensing of Environment, 83, 214-231.

Nichol, C. J., Lloyd, J., Shibistova, O., Arneth, A., Roser, C., Knohl, A., Matsubara, S. \& Grace, J. (2002) Remote sensing of photosynthetic-light-use efficiency of a Siberian boreal forest. Tellus Series B-Chemical and Physical Meteorology, 54, 677-687.

Nichol, C. J., Rascher, U., Matsubara, S. \& Osmond, B. (2006) Assessing photosynthetic efficiency in an experimental mangrove canopy using remote sensing and chlorophyll fluorescence. Trees-Structure and Function, 20, 9-15.

Ogaya, R. \& Peñuelas, J. (2003) Comparative field study of Quercus ilex and Phillyrea latifolia: photosynthetic response to experimental drought conditions. Environmental and Experimental Botany, 50, 137-148.

Papale, D., Reichstein, M., Aubinet, M., Canfora, E., Bernhofer, C., Kutsch, W., Longdoz, B., Rambal, S., Valentini, R., Vesala, T. \& Yakir, D. (2006) Towards a standardized processing of Net Ecosystem Exchange measured with eddy covariance technique: algorithms and uncertainty estimation. Biogeosciences, 3, 571-583.

Peñuelas, J., Filella, I. \& Gamon, J. A. (1995) Assessment of Photosynthetic Radiation-Use Efficiency with Spectral Reflectance. New Phytologist, 131, 291-296.

Peñuelas, J., Llusia, J., Pinol, J. \& Filella, I. (1997) Photochemical reflectance index and leaf photosynthetic radiation-use-efficiency assessment in Mediterranean trees. International Journal of Remote Sensing, 18, 2863-2868.

Rahman, A. F., Cordova, V. D., Gamon, J. A., Schmid, H. P. \& Sims, D. A. (2004) Potential of MODIS ocean bands for estimating $\mathrm{CO}_{2}$ flux from terrestrial 
vegetation: A novel approach. Geophysical Research Letters. doi:10.1029/ $2004 G L 019778$.

Rahman, A. F., Gamon, J. A., Fuentes, D. A., Roberts, D. A. \& Prentiss, D. (2001) Modeling spatially distributed ecosystem flux of boreal forest using hyperspectral indices from AVIRIS imagery. Journal of Geophysical Research, [Atmospheres], $106,33579-33591$.

Rambal, S., Ourcival, J.-M., Joffre, R., Mouillot, F., Nouvellon, Y., Reichstein, M. \& Rocheteau, A. (2003) Drought controls over conductance and assimilation of a Mediterranean evergreen ecosystem: scaling from leaf to canopy. Global Change Biology, 9, 1813-1824.

Reichstein, M., Falge E, D. Baldocchi, D. Papale, M. Aubinet, P. Berbigier, C. Bernhofer, N. Buchmann, T. Gilmanov, A. Granier, T. Grünwald, K. Havránková, H. Ilvesniemi, D. Janous, A. Knohl, T. Laurila, A. Lohila, D. Loustau, G. Matteucci, T. Meyers, F. Miglietta, J. Ourcival, J. Pumpanen, S. Rambal, E. Rotenberg, M. Sanz, J. Tenhunen, G. Seufert, F. Vaccari, T. Vesala, Yakir, D. \& Valentini, R. (2005) On the separation of net ecosystem exchange into assimilation and ecosystem respiration: review and improved algorithm. Global Change Biology, 11, 1424 1439.

Schulze, E. D. (2006) Biological control of the terrestrial carbon sink. Biogeosciences, 3, $147-166$.

Sims, D. A. \& Gamon, J. A. (2002) Relationships between leaf pigment content and spectral reflectance across a wide range of species, leaf structures and developmental stages. Remote Sensing of Environment, 81, 337-354. 
1 Sims, D. A., H. Luo, S. Hastings, W.C. Oechel, Rahman, A. F. \& Gamon, J. A. (2006a)

2 Parallel adjustments in vegetation greenness and ecosystem $\mathrm{CO}_{2}$ exchange in 3 response to drought in a Southern California chaparral ecosystem. Remote Sensing 4 of Environment 103, 289-303.

5 Sims, D. A., Rahman, A. F., Cordova, V. D., El-Masri, B. Z., Baldocchi, D. D., Flanagan, 6 L. B., Goldstein, A. H., Hollinger, D. Y., Misson, L., Monson, R. K., Oechel, W. C., 7 Schmid, H. P., Wofsy, S. C. \& Xu, L. K. (2006b) On the use of MODIS EVI to assess gross primary productivity of North American ecosystems. Journal of Geophysical Research-Biogeosciences G04015, doi:10.1029/2006JG000162.

Tirone, G., S. Dore, G. Matteucci, S. Greco \& Valentini, R. (2003) Evergreen Mediterranean Forests: Carbon and Water Fluxes, Balances, Ecological and Ecophysiological Determinants. IN VALENTINI, R. (Ed.) Fluxes of Carbon, Water and Energy of European Forests. Ecological Studies 163. Berlin, Springer.

Tucker, C. J., Vanpraet, C. L., Sharman, M. J. \& Vanittersum, G. (1985) Satellite RemoteSensing of Total Herbaceous Biomass Production in the Senegalese Sahel - 19801984. Remote Sensing of Environment, 17, 233-249.

Valentini, R., Arriga, N., Mazzenga, F. \& Stefani, P. (2007) Level 4 dataset CEIP_EC_L4_ITCpz_v01 in CarboeuropeIP Ecosystem Component Database http://gaia.agraria.unitus.it/database.

Vermote, E. F., El Saleous, N. Z. \& Justice, C. O. (2002) Atmospheric correction of MODIS data in the visible to middle infrared: first results. Remote Sensing of Environment, 83, 97-111. 
1 Xiao, X. M., Zhang, Q. Y., Hollinger, D., Aber, J. \& Moore, B. (2005) Modeling gross 2 primary production of an evergreen needleleaf forest using MODIS and climate 3 data. Ecological Applications, 15, 954-969. 


\section{$1 \quad$ Figure legends}

3 Figure 1. Seasonal course of daily biophysical variables for the evergreen forest in

4 Castelporziano (2001-2002). A. Gross Primary Productivity (GPP; open circles) and

5 Photosynthetic Active Radiation (PAR; black circles) derived from the eddy covariance

6 tower, B. seasonal dynamics of vegetation indices: Normalized Difference Vegetation

7 Index (NDVI; black squares) and Enhanced Vegetation Index (EVI; open squares), and C.

8 GPP/APAR (black triangles) and Photochemical Reflectance Index (PRI; gray squares).

10 Figure 2. Relationships between daily GPP/PAR and the MODIS spectral indices. A. NDVI

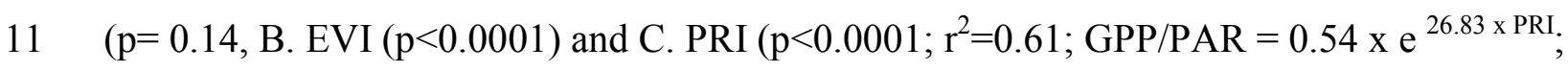

$\left.12 \mathrm{~F}=112.5903 ; \mathrm{n}=51 \mathrm{RMSE}=0.159 \mathrm{~g} \mathrm{C} \cdot \mathrm{MJ}^{-1}\right)$.

14 Figure 3. Relationships between the daily GPP estimated from eddy covariance data and

15 from remote sensing. A. MODIS17 GPP derived from fPAR, climate data, and a RUE

16 estimate based on the maximum ecosystem RUE, the VPD, and the minimum temperature,

17 and B. GPP derived from the novel approach based on PAR, NDVI and PRI suggested

18 here. The use of EVI instead of NDVI as an estimator of fPAR did not improve the GPP

19 estimate (EVI GPP RMSE $=1.6 \mathrm{~g} \mathrm{C} \mathrm{m}^{-2} \mathrm{~d}^{-1}$ vs NDVI GPP RMSE $\left.=1.1 \mathrm{~g} \mathrm{C} \mathrm{m}^{-2} \mathrm{~d}^{-1}\right)$. Black

20 lines are the linear regression between datasets and dotted lines are the 1:1 relationships. 
A

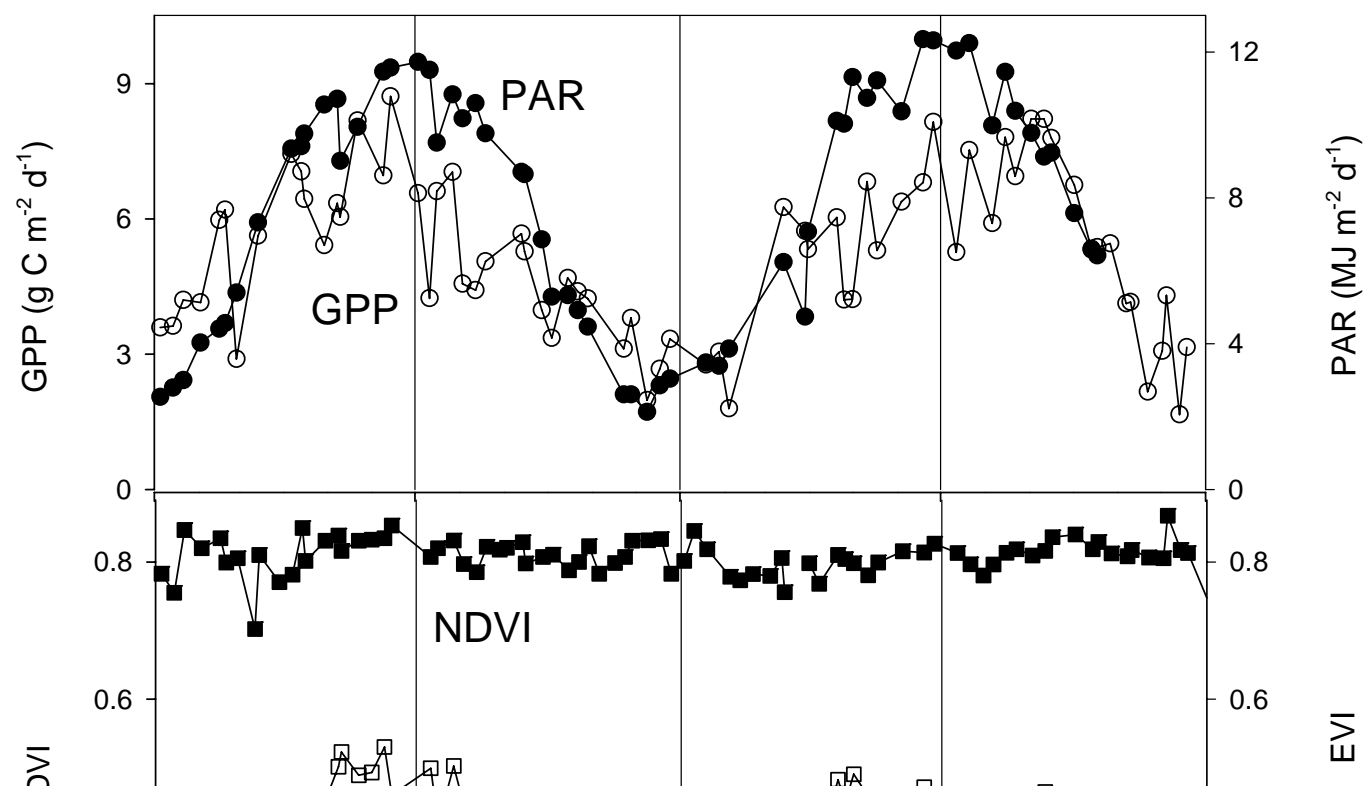

B

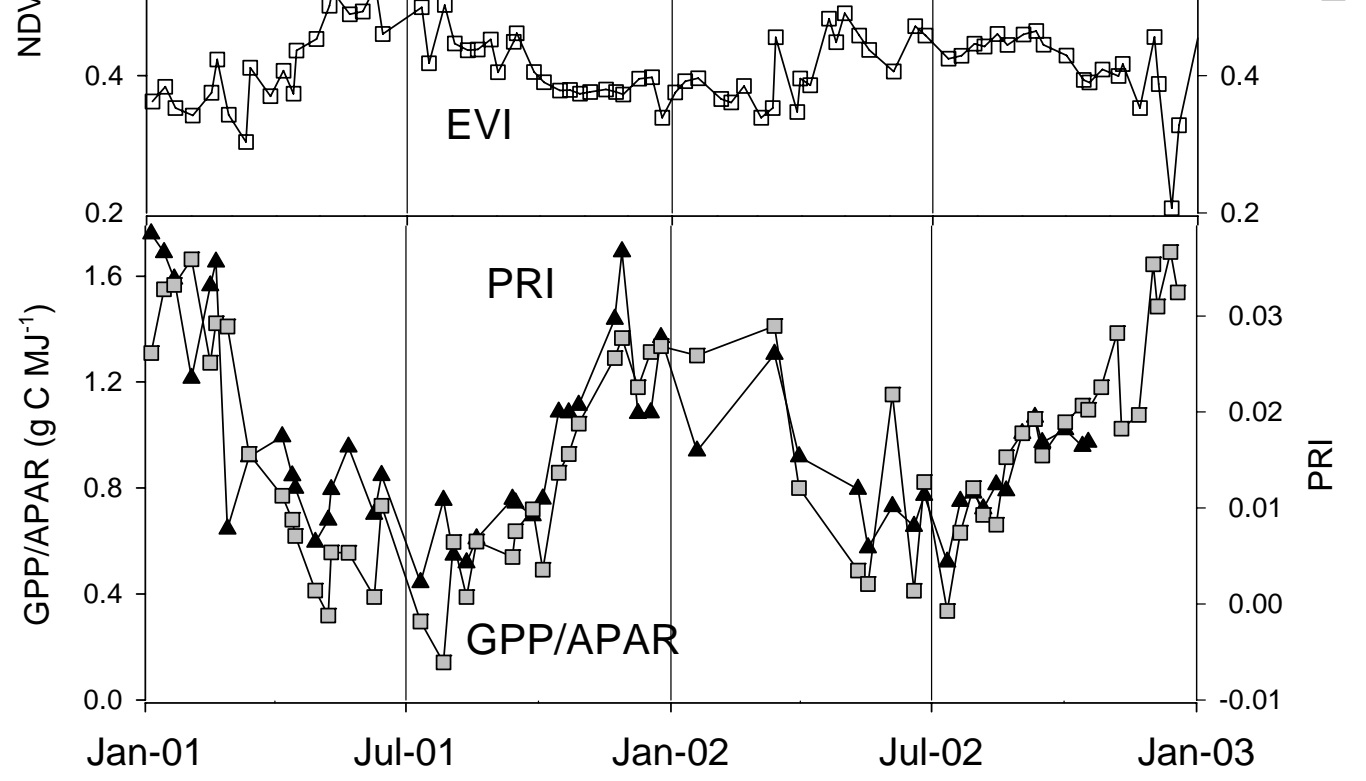

Figure 1. 


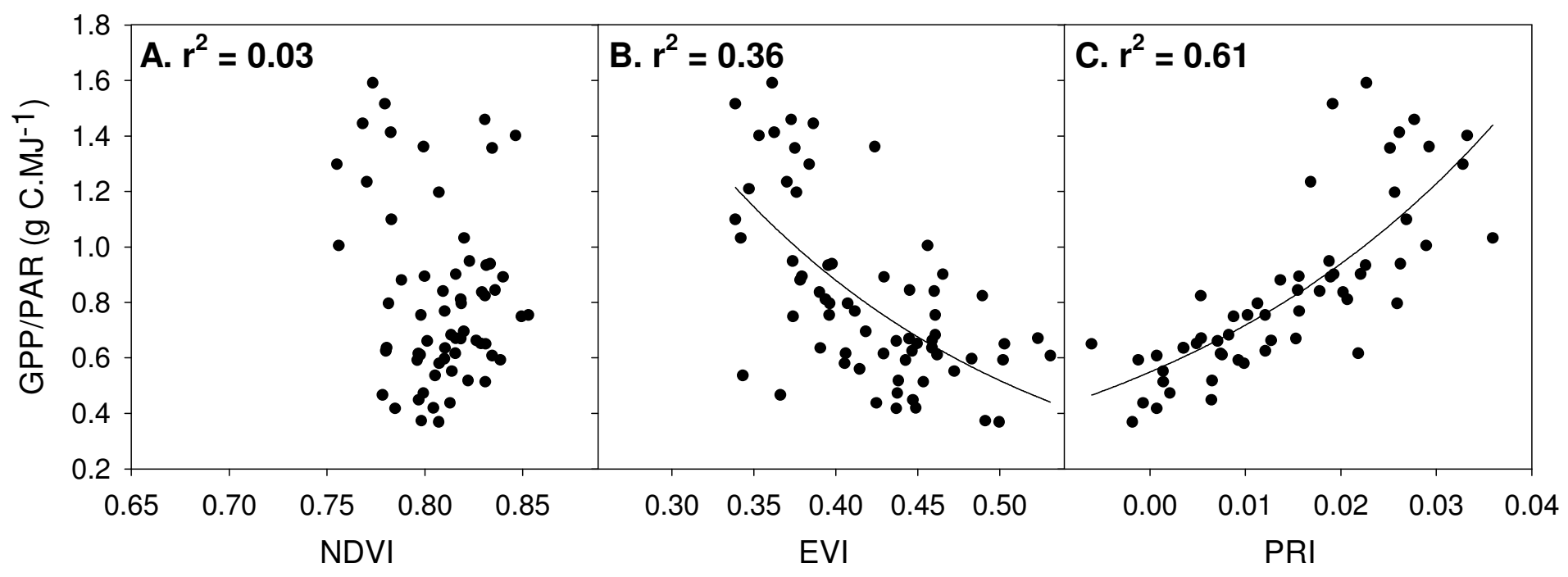

Figure 2. 


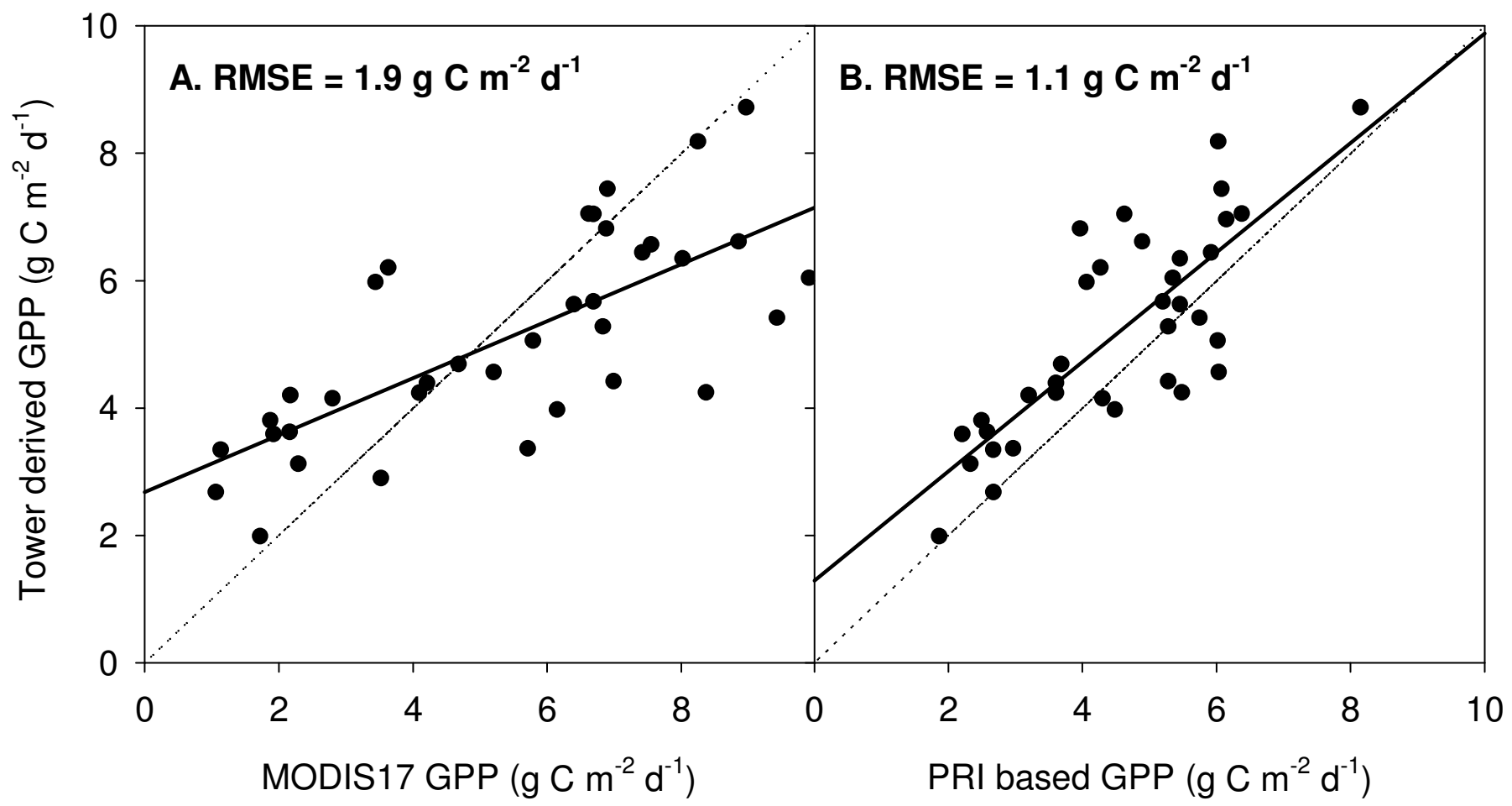

Figure 3. 